\title{
Evaluation of Rodent Fauna of Rural Cutaneous Leishmaniasis Reservoir in East Azerbaijan Province of Iran During 2018-2019
}

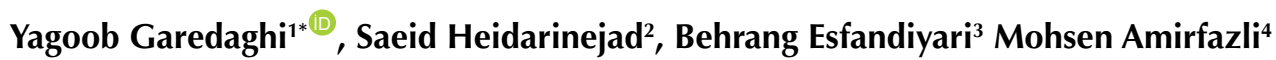 \\ ${ }^{1}$ Department of Parasitology, Tabriz Branch, Islamic Azad University, Tabriz, Iran \\ ${ }^{2}$ Department of biomedical sciences, United States of America, William Carey International University, USA \\ ${ }^{3}$ Postgraduate Student of Veterinary Medicine (D.V.M), Tabriz Branch, Islamic Azad University, Tabriz, Iran \\ ${ }^{4}$ Postgraduate Student of Veterinary Medicine (D.V.M), Shabestar Branch, Islamic Azad University, Shabestar, Iran
}

\begin{abstract}
Introduction: Leishmaniasis is one of the most important parasitic diseases that represents a serious health problem worldwide. This disease exists in three forms: cutaneous (rural, urban), visceral, and mucocutaneous. In the rural type, some rodents play the role of a reservoir. In our country, many people are infected with this disease every year. Cutaneous Leishmaniasis is now common in some parts of East Azerbaijan province. Considering that no comprehensive study on the general condition of cutaneous Leishmaniasis reservoirs in this province has been done so far, this research was very necessary. This study was conducted to investigate the fauna, distribution, and frequency of rodents in East Azerbaijan province from 2018 to 2019.

Methods: This is a descriptive cross-sectional study. Cluster sampling was performed on rodents. Rodents were caught each week by 30 live traps from different parts of East Azerbaijan province and were determined in the laboratory after examining their morphological characteristics. In order to identify Leishmaniasis, 2 samples were prepared from each rodent ear on a laboratory slide and after fixation with methanol and staining by Giemsa method, they were examined by light microscope.

Results: A total of 100 rodents were found in this study, which included 5 species of Rhombomys opimus, Meriones libycus, Mus musculus, Nesokia indica, and Tatera indica. In this study, a total of 3 rodents infected with Leishmania parasite were caught, 2 of which were from Meriones libycus from Azarshahr and Sarab counties and 1 from R. opimus from Kalibar.

Conclusion: Infection of $R$. opimus and M. libycus species was identified in Azarshahr, Sarab, and Kalibar counties. These two species are the most important reservoirs of cutaneous leishmaniasis in Iran. It is suggested that rodents be controlled in areas where there are cases of disease and rodents have been infected with Leishmania parasite in order to control the disease.

Keywords: Cutaneous leishmaniasis, Reservoir, Rodent fauna, East Azerbaijan, Iran
\end{abstract}

Received: September 26, 2019, Accepted: March 22, 2020, ePublished: April 1, 2020

\section{Introduction}

Rodents are mammals that live almost everywhere on land except for the two poles and adapt to different climatic conditions and are widely distributed. Among mammals, rodents are the largest order and the number of species is more than the sum of all other species of mammals $(1,2)$. Moreover, the population of rodents on Earth is probably larger than the total population of other mammals. In our country, rodents make up almost onethird of all mammals in terms of species. Rodents have a lot of reproductive power, so with all the many enemies they have in nature and the heavy casualties they inflict, they are innumerable $(3,4)$. In general, the importance of rodents in terms of public health and agriculture is well known. Mice have been able to move to different parts of the world by ship and with commercial goods and adapt to new environmental conditions. Mice cause harm to humans by damaging food and reducing its value, as well as spreading disease (5). According to the World Health Organization, mice destroy 33 million tons of food annually, which is enough to feed 131 million people (6). One of the problems of rodents in Iran is that they are reservoirs of cutaneous Leishmaniasis and can transmit it to humans (7). In the rural type, the reservoir of the disease is mainly field rodents and so far four species of them are known as the main reservoirs of the disease in Iran (Rhombomys opimus, Meriones libycus, Nesokia indica, and Tatera indica). According to the World Health Organization, leishmaniasis is endemic in 89 countries and more than 350 million people are at risk of contracting the disease $(8,9)$. The number of people with Leishmaniasis is estimated to be 12 million. There are 2 million new cases of leishmaniasis each year, of which about 500000 are estimated to be infected and 1.5 
million are infected with cutaneous Leishmaniasis $(10,11)$. Annually, about 20000 cases of leishmaniasis are reported from our country, but the actual number may be $4-5$ times higher. This disease is endemic in 17 provinces out of 31 provinces of Iran (12).

In East Azerbaijan province, no comprehensive epidemiological study on cutaneous Leishmaniasis has been performed so far. Additionally, considering that this province, with its many historical monuments and buildings, is of interest to domestic travelers and foreign tourists, and if serious measures are not taken to study and control cutaneous leishmaniasis, there is a possibility of spreading the disease to other non-infected parts of the country. The present study was designed and performed to identify rodent faunas in this province and determine disease reservoirs.

\section{Materials and Methods}

This descriptive cross-sectional study was performed from 2018 to 2019. Simple random sampling method was applied. Since it is not possible to determine how many rodents are trapped and caught, the plan did not specify a specific number of rodents in advance. Obviously, the higher the number of specimens caught, the better information is obtained about the species, their distribution, and the prevalence of their infection with the Leishmania parasite. In fact, 9 cities of the province were systematically selected. The number of traps was determined to be 300 per season and a total of 1200 traps were installed and collected during the program. In this study, the rodents were captured with live traps (Sherman). Traps with dimensions of $30 \times 15 \times 10 \mathrm{~cm}$ made of steel or aluminum wires with food (fresh cucumber, dates,) were used. First, suitable places for catching rodents were identified in 10 cities of East Azerbaijan province (Figures 1 and 2). Then, for two years from the beginning of the program, 30 live wire traps were installed once a week near active rodent nests in the selected parts of the province. In these traps, freshly sliced cucumber and dates were used as bait. During the warmer months of the year, traps were set at sunset and collected before sunrise. In the cold months of the year, the traps were installed in the desired locations after sunrise and collected in the afternoon before the temperature dropped. The rodents were anesthetized using chloroform-impregnated cotton plugs - After anesthesia, two slides were prepared from each rodent ear by sanding method. The slides were stained by Giemsa method and examined for leishmaniasis with a 100X objective lens. It took about 20 minutes for each slide to search for the parasite. In addition, the species of the caught rodents were identified according to their morphological characteristics and using the available identification keys. If the rodent had a lesion in the body, sampling was performed from that point.

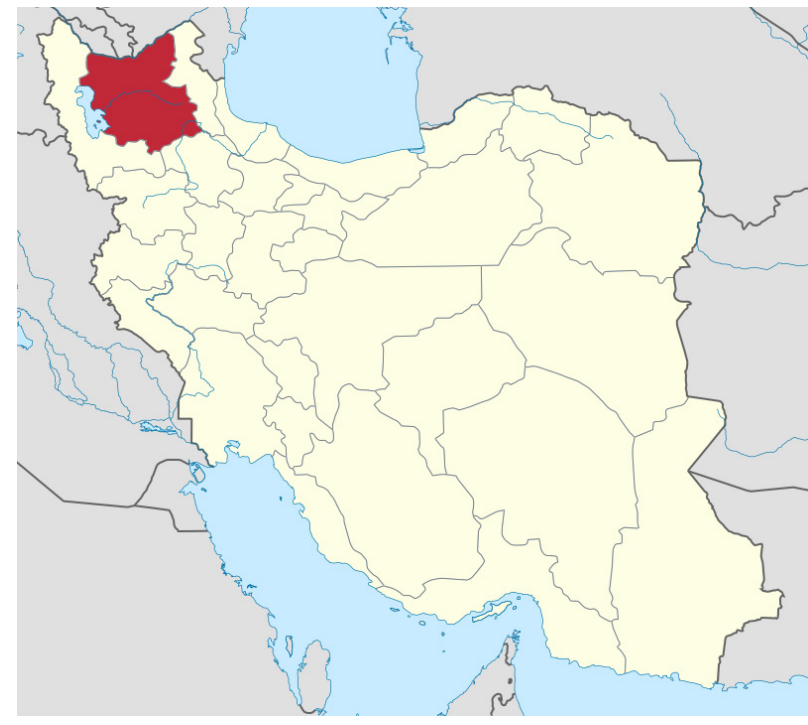

Figure 1. Location of East Azerbaijan Province in Iran.

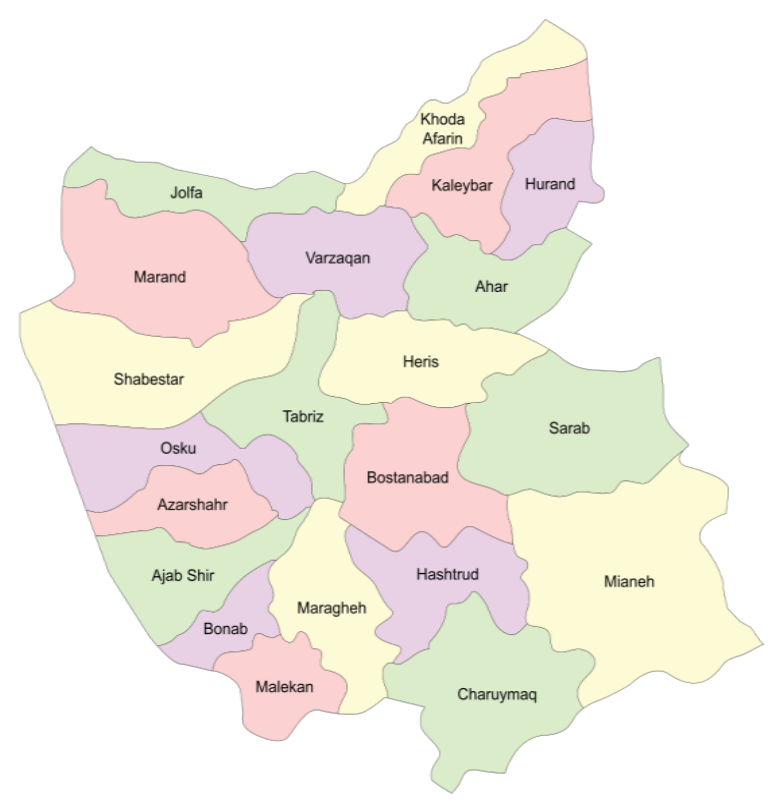

Figure 2. East Azerbaijan Province Counties.

\section{Results}

Determining the Species of Rodents Caught in East Azarbaijan Province

In this study, a total of 100 field rodents were caught, and the existence of 5 species of rodents was confirmed as follows:

Meriones libycus (54\%), Rhombomys opimus (22\%), Mus musculus (13\%), Tatera indica (8\%), and Nesokia indica (3\%) (Table 1).

\section{Determining the Prevalence of Leishmaniasis in the Caught Rodents}

In Azarshahr city, 1 rodent from M. libycus species was infected with Leishmania parasite. In Sarab city, 1 rodent from M. libycus species was also infected with Leishmania 
Table 1. Distribution of the Species Caught in the Cities of East Azerbaijan Province, Iran, During 2018-2019

\begin{tabular}{|c|c|c|c|c|c|c|c|c|c|}
\hline \multirow{2}{*}{ Rodent species } & \multicolumn{9}{|c|}{ Counties } \\
\hline & Varzagan & Azarshahr & Sarab & Mianeh & Kalibar & Hashtrud & Osku & Ahar & Tabriz \\
\hline Rhombomys opimus & - & + & + & + & + & - & - & - & - \\
\hline Meriones libycus & + & + & + & - & + & + & - & - & + \\
\hline Tatera indica & - & - & - & - & - & - & + & - & - \\
\hline Nesokia indica & - & - & - & + & - & + & - & - & - \\
\hline Mus musculus & + & - & - & - & - & - & + & + & + \\
\hline
\end{tabular}

Table 2. Prevalence of Leishmaniasis in Rodents in different Areas of East Azerbaijan Province, Iran, during 2018-2019

\begin{tabular}{|c|c|c|c|c|c|c|c|c|c|c|c|c|}
\hline \multirow{3}{*}{ Rodent Species } & \multicolumn{12}{|c|}{ Counties } \\
\hline & \multicolumn{3}{|c|}{ Azarshahr } & \multicolumn{3}{|c|}{ Sarab } & \multicolumn{3}{|c|}{ Kakibar } & \multicolumn{3}{|c|}{ Total } \\
\hline & $\begin{array}{l}\text { Number } \\
\text { of Tested }\end{array}$ & $\begin{array}{l}\text { Number of } \\
\text { Infected }\end{array}$ & Percent & $\begin{array}{l}\text { Number } \\
\text { of Tested }\end{array}$ & $\begin{array}{l}\text { Number of } \\
\text { Infected }\end{array}$ & Percent & $\begin{array}{l}\text { Number } \\
\text { of Tested }\end{array}$ & $\begin{array}{l}\text { Number of } \\
\text { Infected }\end{array}$ & Percent & $\begin{array}{l}\text { Number } \\
\text { of Tested }\end{array}$ & $\begin{array}{l}\text { Number of } \\
\text { Infected }\end{array}$ & Percent \\
\hline $\begin{array}{l}\text { Rhombomys } \\
\text { opimus }\end{array}$ & 9 & 0 & 0 & 2 & 0 & 0 & 2 & 1 & 50 & 13 & 1 & 7.6 \\
\hline Meriones libycus & 5 & 1 & 20 & 18 & 1 & 5.5 & 6 & 0 & 0 & 29 & 2 & 6.8 \\
\hline
\end{tabular}

parasite. In the city of Kalibar, 1 rodent from R. opimus species was infected with Leishmania parasite (Table 2).

\section{Discussion}

Since rodents are reservoirs of rural cutaneous leishmaniasis, determining their species in East Azerbaijan province, which has several foci of cutaneous leishmaniasis, is very important. In this study, while identifying the existing species, their distribution and level of infection with Leishmania parasite were also determined. According to the findings, 5 species of rodents (R. opimus, M. libycus, M. musculus, N. indica, and T. indica) were caught and identified. Infection of two species of $R$. opimus and M. libycus with Leishmania parasite was also detected in Azarshahr, Sarab, and Kalibar counties. These two species are the most important reservoirs of cutaneous Leishmaniasis in Iran (13-15). In Iran, the infection of 5 rodent species caught in this study with Leishmania parasite has been reported from Gorgan plain, Khorasan, and Isfahan so far. M. libycus has also been reported to be infected with Leishmania in Isfahan, Turkmen Sahara and Azadegan plain $(16,17)$. These rodents have been reported from most parts of Iran, including Sistan and Baluchestan, Kerman, Fars, Khuzestan, Tehran, Qazvin, Kurdistan, Azerbaijan, and Khorasan (18).

The abundance of fleas and lice on the body of house and desert rodents increases the possibility of transmission of some common diseases between humans and rodents; therefore, a more extensive study in this field is needed. Although sanding and sludge preparation from plasma has been used in most articles on cutaneous leishmaniasis reservoirs with positive results, other methods of parasite identification such as polymerase chain reaction are definitely more accurate than direct smear preparation and observation (19-21).

\section{Conclusion}

According to the results of this study and considering that the infection of reservoirs with parasites is one of the most important causes of cutaneous leishmaniasis in an area and no other reservoirs for this disease have been introduced in our country, it may seem that cutaneous Leishmaniasis cannot appear as a major health problem in East Azarbaijan province in the near future. However, considering the cases of the disease in the past and the existence of two important species of disease reservoirs in this region, it is necessary to investigate the contamination level of carrier and reservoir at different times and conduct further studies in this regard. It is suggested that in area, which has cases of disease and in which rodents have been infected with Leishmania parasite, rodents be controlled to control the disease.

\section{Conflict of Interests}

The authors declare that they have no conflict of interests.

\section{Ethical Issues}

In this research, ethical considerations have been fully observed.

\section{Acknowledgements}

We would like to express our deep gratitude to Islamic Azad University Tabriz Branch for offering valuable theoretical and practical assistance to the research team in the present study. Researchers sincerely thank all the esteemed experts who provided the necessary cooperation to conduct this research. We also thank all the respected experts in the fight against diseases in different cities of East Azerbaijan Province for their help in identifying suitable areas for catching rodents.

\section{Authors' Contribution}

YG did writing and SN editing of the manuscript. BE designed and did data collection and MA designed, did data collection and statistical analysis. 


\section{Funding}

The authors received no financial support for the research, authorship, and publication of this article.

\section{References}

1. Talmi-Frank $\mathrm{D}$, Kedem-Vaanunu $\mathrm{N}$, King $\mathrm{R}$, et al. Leishmania tropica infection in golden jackals and red foxes, Israel. Emerg Infect Dis. 2010;16(12):1973-1975. doi:10.3201/eid1612.100953

2. Fikre H, Mohammed R, Atinafu S, van Griensven J, Diro E. Clinical features and treatment response of cutaneous leishmaniasis in North-West Ethiopia. Trop Med Int Health. 2017;22(10):1293-1301. doi:10.1111/tmi.12928

3. van Griensven J, Gadisa E, Aseffa A, Hailu A, Beshah AM, Diro E. Treatment of cutaneous leishmaniasis caused by Leishmania aethiopica: a systematic review. PLoS Negl Trop Dis. 2016;10(3):e0004495. doi:10.1371/journal. pntd.0004495

4. Remadi L, Haouas N, Chaara D, et al. Clinical presentation of cutaneous leishmaniasis caused by Leishmania major. Dermatology. 2016;232(6):752-759. doi:10.1159/000456543

5. Fakhar M, Pazoki Ghohe H, Rasooli SA, et al. Genetic diversity of Leishmania tropica strains isolated from clinical forms of cutaneous leishmaniasis in rural districts of Herat province, Western Afghanistan, based on ITS1-rDNA. Infect Genet Evol. 2016;41:120-127. doi:10.1016/j.meegid.2016.03.031

6. Bhutto AM, Soomro RA, Nonaka S, Hashiguchi Y. Detection of new endemic areas of cutaneous leishmaniasis in Pakistan: a 6-year study. Int J Dermatol. 2003;42(7):543-548. doi:10.1046/j.13654362.2003.01818.x

7. Sharifi I, Fekri AR, Aflatoonian MR, et al. Leishmaniasis recidivans among school children in Bam, South-east Iran, 1994-2006. Int J Dermatol. 2010;49(5):557-561. doi:10.1111/j.1365-4632.2010.04419.x

8. Gitari JW, Nzou SM, Wamunyokoli F, et al. Leishmaniasis recidivans by Leishmania tropica in Central Rift Valley قegion in Kenya. Int J Infect Dis. 2018;74:109-116. doi:10.1016/j.ijid.2018.07.008

9. Dassoni F, Daba F, Naafs B, Morrone A. Leishmaniasis recidivans in Ethiopia: cutaneous and mucocutaneous features. J Infect Dev Ctries. 2017;11(1):106-110. doi:10.3855/jidc. 8516
10. Khanra S, Datta S, Mondal D, et al. RFLPs of ITS, ITS1 and hsp70 amplicons and sequencing of ITS1 of recent clinical isolates of Kala-azar from India and Bangladesh confirms the association of L. tropica with the disease. Acta Trop. 2012;124(3):229-234. doi:10.1016/j.actatropica.2012.08.017

11. Ghatee MA, Mirhendi H, Karamian M, et al. Population structures of Leishmania infantum and Leishmania tropica the causative agents of Kala-azar in Southwest Iran. Parasitol Res. 2018;117(11):34473458. doi:10.1007/s00436-018-6041-1

12. Javadian E. Reservoir host of cutaneous leishmaniasis in Iran. In: Proceeding of the 12th International Congress for Tropical Medicine and Malaria. Amsterdam, New York: Ezcerpta Medica; 1988.

13. Mostafavi E, Parvizi P, Esmaeili S, Alaee-Novin E, Hanifi $H$, Esfandiari B. Investigation of the rodent fauna and the infection status of cutaneous leishmaniasis in some regions western Iran. J Vet Lab Res. 2012;4(1):82. [Persian].

14. Mohammadi S, Sheikhizadeh Aval H. Study on rodent fauna of Ferdows conuty. Exp Anim Biol. 2016;5(1):93-103. [Persian].

15. Gholipoory M, Rezai H, Namroodi S, ArabKhazaeli F. Prevalence of leishmaniasis in rodent's fauna in Turkmen Sahra, Iran. Med Lab J. 2015;9(3):146-151. [Persian].

16. Nadim A, Seyedi-Rashti MA, Mesghali A. Epidemiology of cutaneous leishmaniasis in Turkmen Sahra, Iran. J Trop Med Hyg. 1968;71(9):238-239.

17. Tajedin L, Rassi $Y$, Oshaghi $M$, et al. Study on ectoparasites of Rhombomys opimus, the main reservoir of zoonotic cutaneous leishmaniasis in endemic foci in Iran. Iran J Arthropod Borne Dis. 2009;3(1):41-45.

18. Javadian E, Dehestani M, Nadim A, Rassi Y, Tahvildar-Bidruni GH, Seyedi-Rashti MA, et al. Confirmation of Tatera indica (Rodentia: Gerbilldae) as the main reservoir host of zoonotic cutaneous leishmaniasis in the west of Iran. Iran J Public Health. 1998;27(1 2):55-60.

19. Garedaghi $Y$, Khaki AA. Prevalence of gastrointestinal and blood parasites of rodents in Tabriz, Iran, with emphasis on parasitic zoonoses. Crescent J Med Biol Sci. 2014;1(1):9-12.

20. Edrissian GH, Zovein Z, Nadim A. A simple technique for preparation of smears from the ear of Rhombomys opimus for the detection of leishmanial infection. Trans R Soc Trop Med Hyg. 1982;76(5):706-707. doi:10.1016/0035-9203(82)90255-3

21. Karamian M, Kuhls K, Hemmati M, Ghatee MA. Phylogenetic structure of Leishmania tropica in the new endemic focus Birjand in East Iran in comparison to other Iranian endemic regions. Acta Trop. 2016;158:68-76. doi:10.1016/j.actatropica.2016.02.010

(C) 2020 The Author(s); This is an open-access article distributed under the terms of the Creative Commons Attribution License (http:// creativecommons.org/licenses/by/4.0), which permits unrestricted use, distribution, and reproduction in any medium, provided the original work is properly cited. 